\title{
Experimental and Finite Elements Analysis Study of Warming Effect on Deboned Force for Embedded NiTinol Wire into Linear Low Density Polyethylene
}

\author{
Samir Ali Amin* Ali Yasser Hassan** \\ *, **Department of Mechanical Engineering/ University of Technology \\ *Email: alrabiee2002@yahoo.com \\ ** Email: aliyasir1961@gmail.com
}

(Received 13 December 2017; accepted 7 March 2018)

https://doi.org/10.22153/kej.2018.03.005

\begin{abstract}
This study presents the debonding propagation in single NiTi wire shape memory alloy into linear low-density polyethylene matrix composite the study of using the pull-out test. The aim of this study is to investigate the pull-out tests to check the interfacial strength of the polymer composite in two cases, with activation NiTinol wire and without activation. In this study, shape memory alloy NiTinol wire $2 \mathrm{~mm}$ diameter and linear fully annealed straight shape were used. The study involved experimental and finite element analysis and eventually comparison between them. This pullout test is considered a substantial test because its results have a relation with behavior of smart composite materials. The pull-out test was carried out by a universal tensile test machine type (Laryee), load capacity (50 kN), and a test speed of $1 \mathrm{~mm} / \mathrm{min}$. The finite elements modeling was performed by ANSYS V.15. The results of pull-out test showed that in the activation of NiTinol wire embedded in host matrix linear low-density polyethylene (LLDPE), the deboned force was about $74 \mathrm{~N}$, but for the case without activation, it was about $106 \mathrm{~N}$. Deboned shear stress for the case with activation was about $0.73 \mathrm{MPa}$, but for the case of without activation, it was about 1.05 MPa. ANSYS result for deboned shear stress in case with activation was about $0.8 \mathrm{MPa}$. As for the case of without activation, deboned shear stress was about $0.99 \mathrm{MPa}$. The activation of the ratio of deboned shear stress and deboned force decreased by $30.47 \%$ and $30.13 \%$, respectively. The error ratio between experimental and ANSYS results was equal to $8 \%$ for the case with activation and $5.7 \%$ for the case without activation.
\end{abstract}

Keywords: Activation, Composite Material, Finite Element Modeling, NiTinol Wire, Pull-Out Test, Shape Memory Alloy.

\section{Introduction}

Composite materials are ordinarily employed in structures which require lightweight, yet strong components. There is still a need to enhance these materials, and there is a push to produce materials that have smart properties, which are able to sense, actuate and respond to the surrounding environment. The applications of SMAs in industry are many and variable, for example biomedical, space structures, automobile, vibration, shape control of wings for aero-structures and helicopters. SMAs are also applied in biomedical field, such as heart stents and orthodontics.
Martials without embedded shape memory alloys are nominal materials, but when SMAs are embedded in them, they become composite smart materials.

It is an important test method commonly used to study the interfacial adhesion goodness, interfacial properties and elastic stress transfer between wires and matrix [1,2].

The bonded forces between fiber and host matrix in composite materials play significant role. These forces, which are between the wire and host matrix, depend on the interfacial force.

Jonnalagadda et al. [3] studied the effect of different surfaces treatments of NiTinol wires into 
host material to find the bond force utilize pull-out tests. Several curing was inspected: untreated, acidetched, hand sanded, and sandblasted. The highest bond force was provided by sandblasting, while acid etching and hand sanding were less effective manners of improvement the bond force properties.

N. A. Smith et al. [4] studied the improvement of adhesion bond between the NiTi wire and Silane coupling agents as the host matrix. Black oxidecoated NiTi wire (0.03 inch diameter, NiTinol Devices and Components, $\mathrm{A}_{\mathrm{f}} 80^{\circ} \mathrm{C}$ ) was excavated (20 min. sonication in conc. $\mathrm{H}_{2} \mathrm{SO}_{4}$ ), degreased (Hexanes, Isopropyl alcohol and Ultrapure $\mathrm{H}_{2} \mathrm{O}$ [Millipore]; $20 \mathrm{~min}$. sonication in each solvent), and exposed to a base/acid sequence to enhance the concentration of surface hydroxides $(20 \mathrm{~min}$. sonication in $1 \mathrm{M} \mathrm{NaOH}, 5$ min. sonication conc. $\mathrm{H}_{2} \mathrm{SO}_{4}$ ). X-ray Photoelectron Spectroscopy was employed. The results indicated increasing of interfacial bonded roughly $100 \%$.

Sadrnezhaad et al. [5] estimated the bond conduct between NiTinol and a silicone matrix for medical applications. NiTinol wires with various surface curing were examined by (SEM), and pullout tests were led to determine the Morph-logical and bonding interactions with the silicone host matrix. Acid and oxidization increased the fricative forces at the interface which produced an increase in the bond force.

Xiaoling Wang and Gengkai $\mathrm{Hu}$ [6] investigated the influence of temperature on the stress transfer during a pull out of a SMA fiber from an elastic matrix. The results proved that the increase of temperature decreases the stress intensity factor.

Wambura Mwiryenyi Mwita [7] studied the effect of embedded NiTinol wire (1 mm diameter) into polyurethane matrix in a silicon mold, prestrain technique was employed to stretch the wire by 3\%. Pull-out test and four-point bending test were performed. Increasing in the flexural stiffness (EI) and fracture stress intensity factor $\left(\mathrm{K}_{\mathrm{IC}}\right)$ of the composites plate was deduced. It was shown that the deboned force decreased when activating SMA.

Payandeh et al. [9] investigated the effect of the transformation on the debonded inception in without pre-strained NiTinol wire-epoxy matrix composites. NiTinol wires were embedded in an epoxy coupon to achieve $6 \%$ and $12 \%$ NiTinol wires volume fractions. Epoxy coupons with NiTinol wires volume fractions of $6 \%$ were tested in tension at $20^{\circ} \mathrm{C}, 80^{\circ} \mathrm{C}$, and $90^{\circ} \mathrm{C}$, whereas samples with NiTinol wires volume fractions of $12 \%$ were examined at $80^{\circ} \mathrm{C}$ and $90^{\circ} \mathrm{C}$. Increasing the NiTinol wires volume fraction improved the mechanical conduct of the composite.

Mattia Merlin et al. [9] investigated the effect of different surface treatments on the shape memory alloy NiTinol wires into Polyester (PE) and Vinyl Ester (VE) polymeric matrices. NiTinol wire of diameter $0.5 \mathrm{~mm}$ was employed as fiber in this research. Three types of recovery strain used, the first $4 \%$, the second $5 \%$ and the third $6 \%$. Two types of chemical etching and a chemical bonding with a Silane coupling agent were carried out on the surfaces of the wires. The results showed that the wires embedded in the PE resin indicated the maximum pull-out forces and the highest interfacial adhesion. Eventually, it was found that the debonding induced by strain recovery is strongly related to the propagation towards the radial direction of sharp cracks at the debonding region.

The aim of this research is to investigate pullout tests to check the interfacial strength of the polymer composite in two cases, with activation NiTinol wire and with-out activation.

\section{Experimental Work}

The experimental work is divided into two parts, the first part is manufacturing the injection mold for the composite model, and the second part is preparing the NiTinol wire to injection. The testing is classified into two types, the first test is the pull-out test without activation NiTinol wire, and the second test is the pull-out test with activation NiTinol wire.

\subsection{The Used Materials}

(i) The matrix (Host):

In this work, a linear low density polyethylene (LLDPE) host material with a density about (0.92$0.93) \mathrm{gm} / \mathrm{cm}^{3}$ was used [10]. Melting temperature of the host material is about $122.7^{\circ} \mathrm{C}$, which was obtained by DSC test. Plastic in form of grains was obtained from the Sabic Company in Saudi Arabia. (ii) The NiTinol wire:

In this research, a high temperature about $80^{\circ} \mathrm{C} \pm 10^{\circ} \mathrm{C}$ NiTinol wire, full annealed, $(2 \mathrm{~mm})$, with a straight shape and black color was employed, it consists of (Ni-55\%, H-0.001\%, O$0.05 \%, \quad \mathrm{~N}-0.001 \%, \quad \mathrm{C}-0.05 \%, \quad$ Ti-Balance), exported from Nexmetal Inc. 8780 19th Alta Loma, California 91701.

The general properties of NiTinol wire are shown in table (1): 
Table 1,

Mechanical properties of NiTinol wire [11]

\begin{tabular}{|c|c|}
\hline Property & Value \\
\hline Color & Black \\
\hline Primary Fiber Direction & (Unidirectional) \\
\hline Density $\left(\mathrm{kg} / \mathrm{m}^{3}\right)$ & 6450 \\
\hline $\begin{array}{l}\text { Thermal expansion coefficient } \\
\left(10^{-6} \mathrm{~K}^{-1}\right)\end{array}$ & $6.6-11$ \\
\hline Resistivity $(\mu \Omega \mathrm{cm})$ & $80-100$ \\
\hline Thermal conductivity $\left(\mathrm{W} \mathrm{m}{ }^{-1} \mathrm{~K}^{-1}\right.$ ) & $10-18$ \\
\hline Melting temperature $(\mathrm{K})$ & 1573 \\
\hline Heat capacity $\left(\mathrm{J} \mathrm{kg}^{-1} \mathrm{~K}^{-1}\right)$ & 390 \\
\hline $\begin{array}{l}\text { Young modulus (austenite) } \\
\text { (GPa)(test) }\end{array}$ & 60000 \\
\hline $\begin{array}{l}\text { Young modulus (martensite) } \\
\text { (GPa)tested }\end{array}$ & 20000 \\
\hline $\begin{array}{l}\text { Austenite finish temperature }\left(A_{f}\right) \\
(K) \text { tested }\end{array}$ & 343 \\
\hline $\begin{array}{l}\text { Austenite start } \\
\text { temperature }\left(\mathrm{A}_{\mathrm{s}}\right)(\mathrm{K}) \text { tested }\end{array}$ & 331 \\
\hline
\end{tabular}

\subsection{DSC Test of Polymer (LLDPE)}

Differential Scanning Calorimeter (DSC) is used to study the response of polymers to heating. DSC can be used to find the melting temperature or the glass transition temperature. The DSC set-up is composed of a measurement chamber and a computer. Two pans are heated in the measurement chamber. A computer is used to monitor the temperature and regulate the rate at which the temperature of the pans changes. A typical heating rate is around $10^{\circ} \mathrm{C} / \mathrm{min}$.

DSC test was done in University of Baghdad, College of Education for Pure Sciences Ibn ALHaitham Central Service Laboratory. From this test, the melting temperature obtained was about $122.7^{\circ} \mathrm{C}$ for polymer (LLDPE), as shown in figure (1).

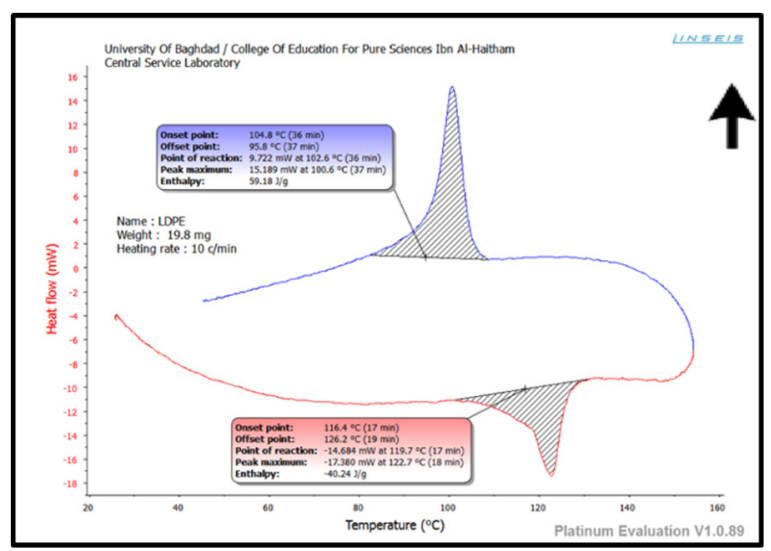

Fig. 1. DSC Test Diagram of melting temperature for (LLDPE).

\subsection{Design and Manufacture of an Injection Mold}

The injection mold was designed by Auto CAD program. The mold consists of three parts, upper, middle and lower part. The middle part called cavity part consisting of holes in every side was produced to pass the NiTinol wire through them. The lower part was used to cool the sample model in cavity after the injection process. All parts are made from steel except the lower part is made from aluminum, to speed up the cooling process. The manufactured injection mold is shown in figure (2).

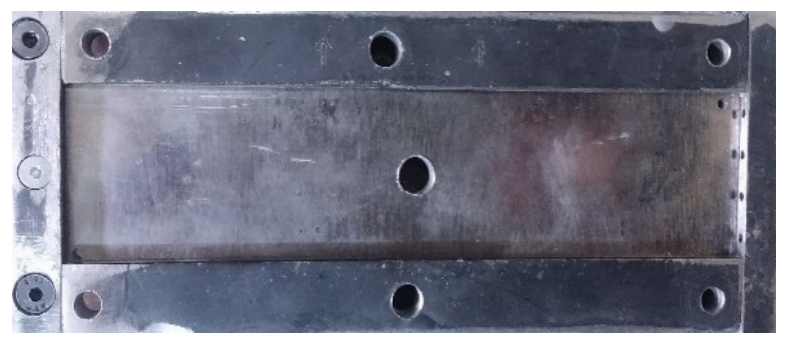

Fig. 2. The manufactured injection mold.

\subsection{Pull-Out Unidirectional NiTinol Wire without Activation}

Pull-out test was conducted in order to estimate the deboned load and maximum interfacial shear stress between the matrix (host material) LLDPE and NiTinol wires. The dimensions of the pull-out test specimen and pullout specimen are shown in figures (3) and (4), respectively.

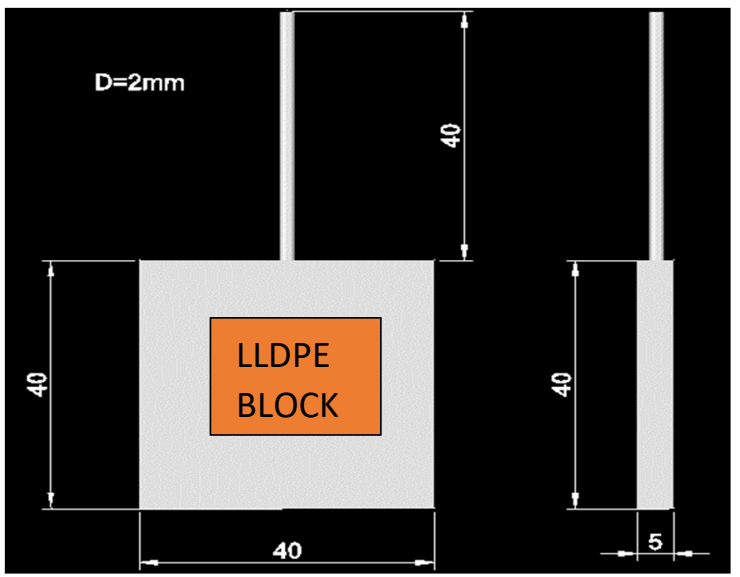

Fig. 3. Pull-out specimen with dimension in $\mathbf{m m}$. 


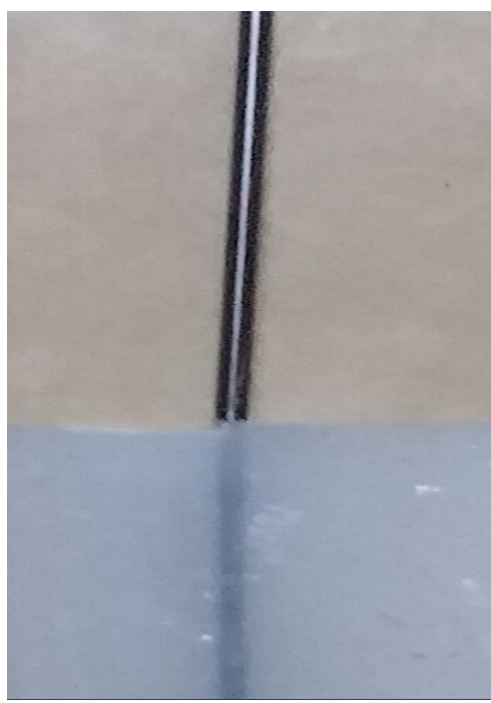

Fig. 4. Pull-out specimen

The dimensions of the block are $(\mathrm{L}=40 \mathrm{~mm}$, $\mathrm{W}=40 \mathrm{~mm}$, and $\mathrm{t}=5 \mathrm{~mm}$ ) and length of NiTinol wire embedded in polymer block is $\mathrm{L}_{\mathrm{e}}=40 \mathrm{~mm}$ [12]. A universal tensile test machine type (Laryee), load capacity $(50 \mathrm{kN})$, and a test speed of $1 \mathrm{~mm} / \mathrm{min}$ were used, the pull-out test is shown in figure (5). From the pull-out test, the relationship between applied load and NiTinol wire displacement was plotted.

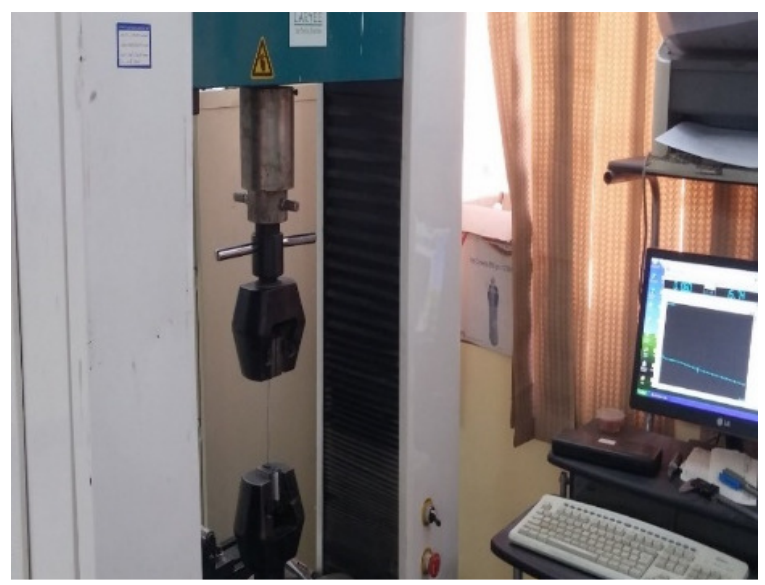

Fig. 5. Pull-out specimen during testing by tensile universal machine.

\subsection{Pull-Out Unidirectional NiTinol Wire with Activation}

The aim of this test is to investigate the effect of activation temperature of NiTinol wire embedded in polymer matrix due to evaluated heat of polymer surface. Another sample was used here with a same dimension, the NiTinol wire was connected with a power supply and subjected to a current about 7.1A, and after specified time, the temperature of surface sample became $45^{\circ} \mathrm{C}$. A universal tensile testing machine type (Laryee), load capacity (50 $\mathrm{kN})$, and test speed of $1 \mathrm{~mm} / \mathrm{min}$ as were used shown in figure (7).

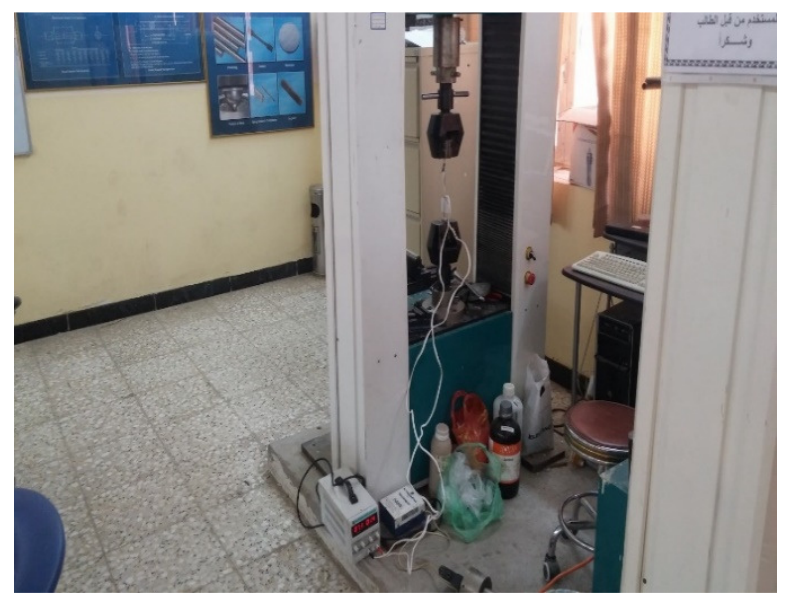

Fig. 6. Pull-out specimen during the activation.

\section{FE Modeling of Pull-Out Test Model}

The pull-out tests are classified into two tests, the first test was performed without activation of NiTinol wire, and the second test was conducted with activation the NiTinol wire.

\subsection{FE Modeling of Pull-Out Test Model without Activation}

The model 3D pull-out test was created in ANSYS V.15. Rectangular block has dimensions ( $\mathrm{L}=40 \mathrm{~mm}, \mathrm{w}=40 \mathrm{~mm}, \mathrm{t}=5 \mathrm{~mm}$ ), and NiTinol wire

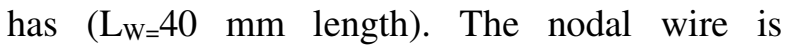
connected with nodes for the rectangular after generation of nodes. The spring between the nodes embedded in the block gives the set of the functions between the effected force and displacement of wire. In this analysis, three types of elements were employed, the first element is 3D solid185 used for polymer host matrix a (LLDPE), the second element is link 180 used for NiTinol wire with cross sectional area $3.14 \mathrm{~mm}^{2}$ and the third element is combin39 used to bond the nodes into the matrix. The pull-out model with meshing is shown in figure (8). This model applied the displacement on the tip of the end of the wire, and all the area of rectangular block is fixed. 


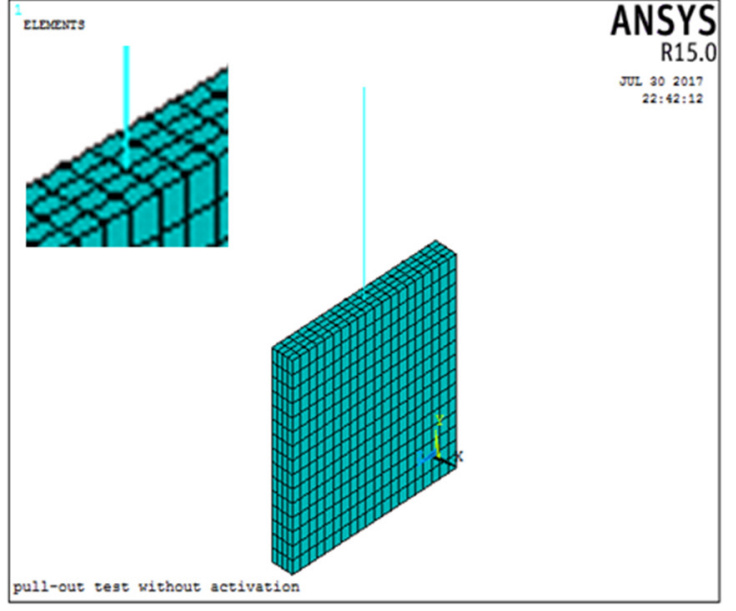

Fig. 7. Meshing of finite element 3D model of pullout test.

\subsection{FE Modeling of Pull-Out Test Model with Activation}

The model of pull-out test applied in ANSYS codes is the same, but here some functions used in ANSYS codes must be given to explain the relationship between the deboned force and displacement of wire through the motion. The model meshing is the same in figure (8). The maximum interfacial stress was calculated according to the equation (1): [13]

$\tau_{\text {imax }}=\frac{F_{d}}{\pi * d_{f *} l_{e}}$

Where;

$\tau_{\text {imax }}:$ Deboned shear stress $(\mathrm{MPa})$

$\mathrm{F}_{\mathrm{d}}$ : Deboned force $(\mathrm{N})$

$1_{\mathrm{e}}$ : NiTinol wire embedded length $(\mathrm{m})$

$d_{f}$ : Diameter of wire

\section{Results and Discussion}

\subsection{Results of Experimental Work}

The pull-out test was used to calculate the maximum deboned shear stress between NiTinol wire and polymeric host material. Shear stress can be calculated by considering the diagram between the deboned force and displacement using equation (1). The main purpose of using the NiTinol wire in composite is to carry the load applied to composite, while the matrix holds and protects the wire, thus distributing the load between them [10]. This curve before activation NiTinol wire is shown in figure (9).

The second pull-out test included activation NiTinol wire with suitable current by using DC power supply. The relationship between the deboned force and the displacement in activation case is shown in figure (10).

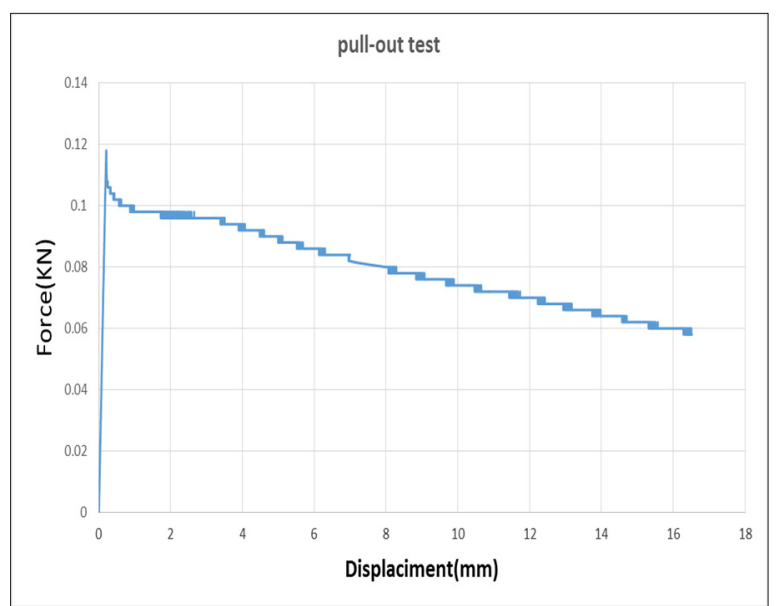

Fig. 8. Pull-out test of NiTinol wire without activation

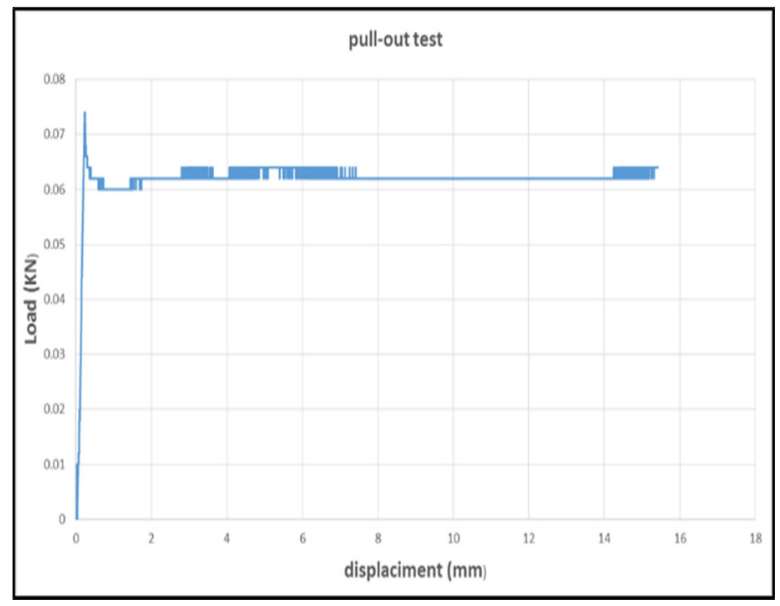

Fig. 9. Pull-out test of NiTinol wire with activation

\subsection{Finite Element Modeling Results}

From finite element analysis using ANSYS V. 15 , one can get the contour of deboned shear stress without activation and with activation, as shown in figures (11) and (12), respectively. These results are in agreement with reference [7]. 


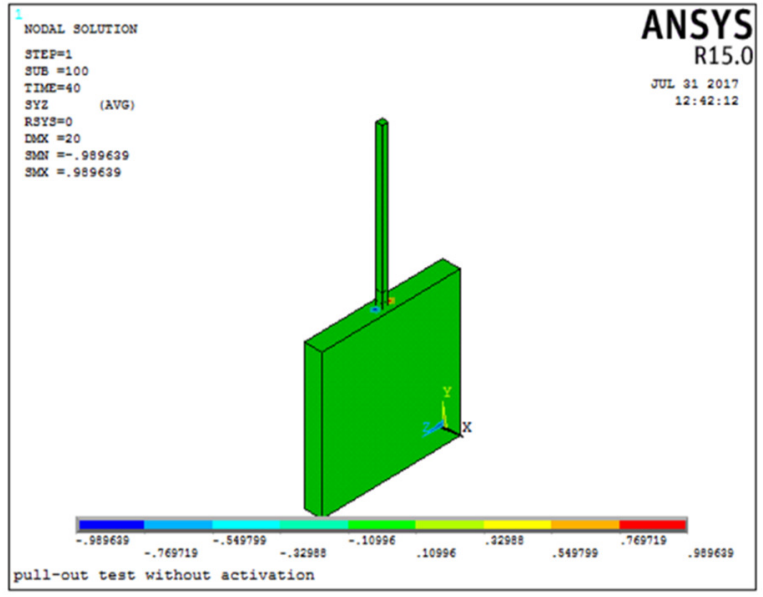

Fig. 10. Contour of deboned shear stress without activation wire.

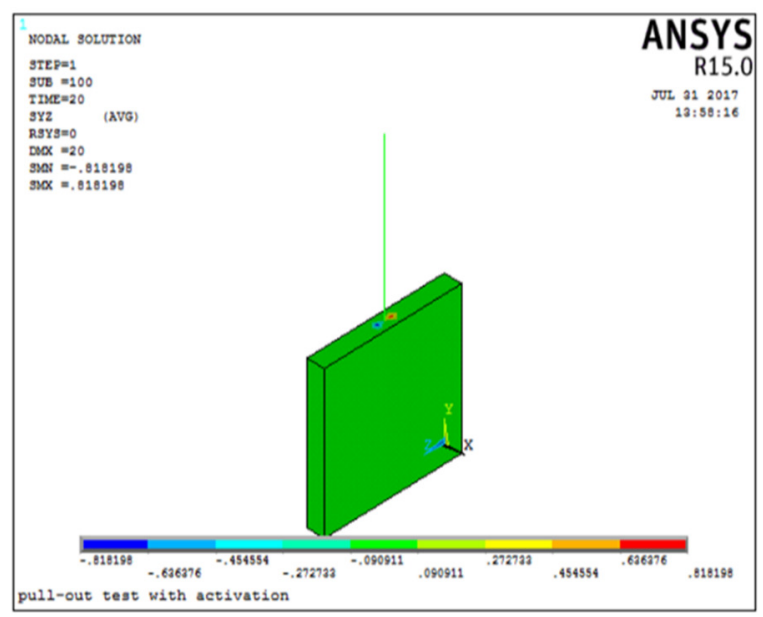

Fig. 11. Contour of deboned shear stress with activation wire.

It clear now that in the activation NiTinol wire embedded in host matrix (LLDPE), the deboned force and shear stress are decreased, all the results are explained in table (2) below. Through activation, the ratio of shear stress deboned and force deboned decreased by $30.47 \%$ and $30.13 \%$, respectively.

Table 2,

Results of pull-out test in experimental and finite element modeling

\begin{tabular}{lllll}
$\begin{array}{l}\text { Type of } \\
\text { test }\end{array}$ & \multicolumn{2}{l}{ Experimental } & ANSYS & $\begin{array}{l}\text { Error } \\
\text { ratio }\end{array}$ \\
\cline { 2 - 4 } & $\begin{array}{l}\text { Deboned } \\
\text { force } \\
(\mathbf{N})\end{array}$ & $\begin{array}{l}\text { Deboned } \\
\text { shear } \\
\text { stress } \\
(\mathbf{M P a})\end{array}$ & $\begin{array}{l}\text { Deboned } \\
\text { shear } \\
\text { stress } \\
(\mathbf{M P a})\end{array}$ & \\
\cline { 2 - 4 } & 74 & 0.73 & 0.8 & $8 \%$ \\
$\begin{array}{l}\text { With } \\
\text { activation }\end{array}$ & & 1.05 & 0.99 & $5.7 \%$ \\
$\begin{array}{l}\text { Without } \\
\text { activation }\end{array}$ & 106 & & & \\
\hline
\end{tabular}

\section{Conclusions}

In this research, the pull-out test in both cases was investigated, the first is with activation NiTinol wire and the second is without activation NiTinol wire. The following conclusions have drawn from this work:

1. In pull-out test, the activation decreases the deboned force.

2. Activation of NiTinol wire tends to decrease the deboned shear stress.

3. Through activation, shear stress deboned and force deboned are decreased by $30.47 \%$ and $30.13 \%$, respectively.

4. These results are beneficial for the design of smart composite materials.

5. A good agreement was found between the experimental and ANSYS results with a maximum percentage of error $8 \%$ with activation and $5.7 \%$ without activation.

\section{Notation}

$\begin{array}{ll}\text { LLDPE } & \text { Linear low density polyethylene } \\ \text { SAM } & \text { Shape memory alloy } \\ \text { SME } & \text { Shape memory effect } \\ \text { SEM } & \text { Scanning electron microscopy } \\ \text { DC } & \text { Direct current } \\ \text { PE } & \text { Polyester } \\ \text { VE } & \text { Vinyl Ester }\end{array}$

\section{Acknowledgements}

The authors gratefully acknowledged Materials Engineering Department in University of Technology for providing the needed devices for experiments and for the support this work.

\section{References}

[1] Zhou, L.-M., Kim, J.-K., Mai and Y.-W., Interfacial debonding and fiber pull-out stresses. Part II a new model based on the fracture mechanics approach, J. Mater. Sci., 27 (1992) 3155-3166.

[2] Zhou, L.-M., Mai, Y.-W. and Baillie, C., Interfacial debonding and fiber pull-out stresses. Part V A methodology for evaluation of interfacial properties, J. Mater. Sci., 29 (1994) 5541-5550.

[3] Jonnalagadda K, Kline G and Sottos N. Local displacements and load transfer in shape memory alloy composites. Exp. Mech 1997; 37(1):78-86. 
[4] N.A. Smitha, G. G. Antounb, A. B. Ellisa, and W.C. Cronec. "Improved adhesion between nickel-titanium shape memory alloy and a polymer matrix via silane coupling agents", Composites: Part A 35 (2004) 1307-1312.

[5] Sadrnezhaad S, Nemati N and Bagheri R. Improved adhesion of NiTi wire to silicone matrix for smart composite medical applications. Mater Design 2009; 30(9):366772.

[6] Xiaoling Wang and Gengkai Hu," Stress transfer for a SMA fiber pulled out from an elastic matrix and related bridging effect", Composites: Part A 36 (2005) 1142-1151.

[7] Wambura Mwiryenyi Wita,"Development and Testing an Intelligent Hybrid Polymeric Composite Beam With Healing Ability Embedded with NiTinol Shape Memory Alloy Embedded with Ni-Ti Shape Memory Alloy“, MSc Thesis, Cape Peninsula University of Technology , Faculty of Engineering, Department of Mechanical Engineering, December (2010).

[8] Payandeh Y, Meraghni F, Patoor E, and Eberhardt A. Study of the martensitic transformation in NiTi-epoxy smart composite and its effect on the overall behavior. Mater Design 2012; 39:104-10.

[9] Mattia Merlin, Martina Scoponi, Chiara Soffritti, Annalisa Fortini, Raffaella Rizzoni and Gian Luca Garagnani.," On the improved adhesion of NiTi wires embedded in Polyester and Vinylester resins", M. Merlin et alii, Fracture ed Integrate Structural, 31 (2015) 127-137; DOI: 10.3221/IGF-ESIS.31.10.
[10] C. S. Cai, Wenjie Wu, Suren Chen, and George Voyiadjis," Applications of Smart Materials in Structural Engineering", Department of Civil Engineering, Louisiana State University, State Project No. 736-991055, October 2003.

[11] F. Calkins, J. Mabe, R. and Ruggeri," Overview of Boeing's shape memory alloy based morphing aerostructures", Proceedings of SMASIS08: ASME Conference on Smart Materials, Adaptive Structures and Intelligent Systems, October 28-30, 2008, Ellicott City, MD (2008).

[12] Ali Sadiq Yasser," The Effect of Fiber PreTension on the Static and Dynamic Behavior of Composite Plates", PhD thesis, Machines and Equipment Engineering Departments, University of Technology, (2001).

[13] William F. Smith and Javad Hashmi, Handbook, "Foundations of Materials Science and Engendering “, Fourth edition (2006). 1088 pages, McGraw-Hill Education. 


\title{
دراسة عملية وتحليل العناصر المحدة لتاثير التسخين على قوة الانسلاخ لسلك النيتينول مغمور داخل بولي اثيلين خطي منخفض الثضير الكثافة
}

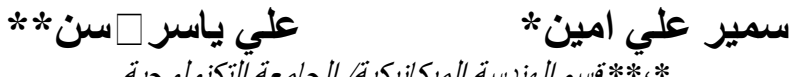

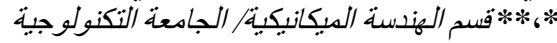 \\ alrabiee2002@yahoo.com البريد الالكتروني: \\ aliyasir1961@gmail.com:البريد الالكتروني: البروني:
}

هذا البحث يقدم در اسة نشوء الانسلاخ لسلك نيتينول مفرد سبيكة ذاكرة الثكل داخل بولي اثثلين خطي منخفض الكثافة مصفوفة مركبة در اسة باستخدام

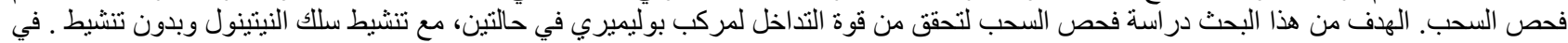

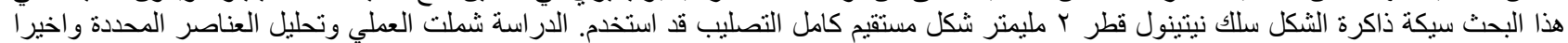

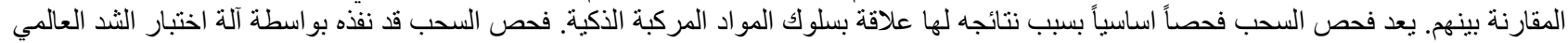

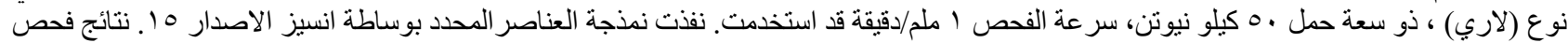

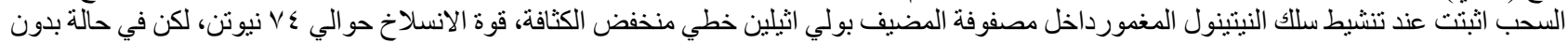

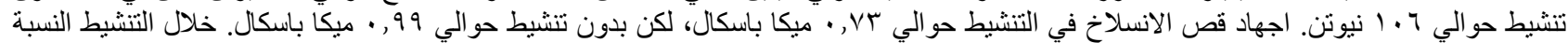

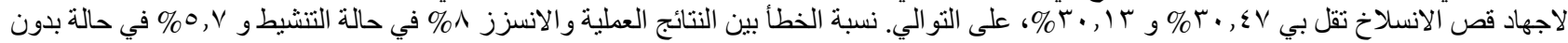

